\title{
Effect of Load Model Using Ranking Identification Technique for Multi Type DG Incorporating Embedded Meta EP-Firefly Algorithm
}

\author{
Siti Rafidah Abdul Rahim ${ }^{* 1}$, Ismail Musirin², Muhammad Murtadha Othman², and Muhamad Hatta Hussain ${ }^{3}$ \\ ${ }^{1}$ Center of Excellence for Renewable Energy (CERE), UniMAP, Universiti Malaysia Perlis, 02600, Arau, Perlis, Malaysia. \\ ${ }^{2}$ Center for Electrical Power Engineering Studies, Faculty of Electrical Engineering, Universiti Teknologi MARA, 40450 Shah Alam, \\ Malaysia \\ ${ }^{3}$ School of Electrical System Engineering, Universiti Malaysia Perlis, 02600, Arau, Perlis, Malaysia
}

\begin{abstract}
This paper presents the effect of load model prior to the distributed generation (DG) planning in distribution system. In achieving optimal allocation and placement of DG, a ranking identification technique was proposed in order to study the DG planning using pre-developed Embedded Meta Evolutionary Programming-Firefly Algorithm. The aim of this study is to analyze the effect of different type of DG in order to reduce the total losses considering load factor. To realize the effectiveness of the proposed technique, the IEEE 33 bus test systems was utilized as the test specimen. In this study, the proposed techniques were used to determine the DG sizing and the suitable location for DG planning. The results produced are utilized for the optimization process of DG for the benefit of power system operators and planners in the utility. The power system planner can choose the suitable size and location from the result obtained in this study with the appropriate company's budget. The modeling of voltage dependent loads has been presented and the results show the voltage dependent load models have a significant effect on total losses of a distribution system for different DG type.
\end{abstract}

\section{Introduction}

The terms of distributed generation (DG) is small generating units installed at strategic points of the distribution system. The introduction of DG on the distribution network can significantly impact the flow of power, voltage conditions and power quality at customers and utility equipment [1]. The ranking identification technique is developed in order to determine the suitability of DG planning in the distribution system. This technique was conducted using the developed automatic algorithm for single DG by incorporating the Embedded Meta EP-Firefly Algorithm (EMEFA) technique as optimization technique[2]. In this study, the different loads are modeled prior to the different DG type installation for single objective implementation considering loss minimization.

The load in the distribution system is divided into three categories i.e. residential, commercial and industrial. These three load types are voltage dependent, and active and reactive power components respond differently to variations in voltage. The voltage dependent load has a main impact on distribution system planning studies. The load models termed as residential, commercial, industrial and mixed loads will give impact to active and reactive intake power and system losses [3][4].
The research to date has tended to focus on the loss minimization scheme of DG capacities where the locations are dependent on the load model. However, in this study, the proposed technique was also performed for different type of DG. The analysis was performed in order to investigate the effect of the different load model during DG installation. Detailed explanations on each procedure are described in the sub-sections. In this study, the convergence is set to 100 iterations in order to minimize the burdensome on the optimization. The iteration is set to that value in order to limit the computational time due to improper location. This situation may refer as the location is not suitable to locate any DG or not recommended to install the DG due to the system did not converge.

\section{Methodology}

Generally, in most distribution system studies, it is assumed that active and reactive power demands are constant values (i.e., constant power model). However, in actual distribution systems, different categories of load models or even mix of load might be present for the system [5]. The nature of these types of loads is such that their active and reactive powers are voltage dependent. Moreover, load characteristics have considerable effects on power flow solutions and system power losses.

\footnotetext{
* Corresponding author: rafidah@unimap.edu.my
} 
The loss minimization is required in determining the size of DG. First, $A_{i j}$ and $\mathrm{B}_{i j}$ need to be obtained using equation (2) and (3) and then these values are substituted into equation (1) to calculate the total line losses in the system:

$$
\begin{aligned}
& P_{\text {loss }}=\sum_{i=1}^{n} \sum_{j=1}^{n} A_{i j}\left(P_{i} P_{j}+Q_{i} Q_{j}\right)+B_{i j}\left(Q_{i} P_{j}-P_{i} Q_{j}\right) \\
& A_{i j}=\frac{R_{i j} \cos \left(\delta_{i}-\delta_{j}\right)}{V_{i} V_{j}} \\
& B_{i j}=\frac{R_{i j} \sin \left(\delta_{i}-\delta_{j}\right)}{V_{i} V_{j}}
\end{aligned}
$$

$P_{i}$ and $Q_{i}$ are real and reactive power of bus $i$ respectively, $P_{j}$ and $Q_{j}$ are the real and reactive power of bus $j$ respectively, $R_{i j}$ is the line resistance between bus $i$ and bus $j, V_{i}$ and $V_{j}$ are the voltage magnitude at bus $i$ and bus $j$ respectively, and $\delta_{i}$ and $\delta_{j}$ are the voltage angle of bus $i$ and bus $j$ respectively. Due to the main objective to study the effect of load model prior to the DG installation for single objective implementation considering loss minimization, the optimization technique is to minimize the total real power loss, so the $P_{\text {loss }}$ is subjected into the objective function, $O f$ which can be described in (4).

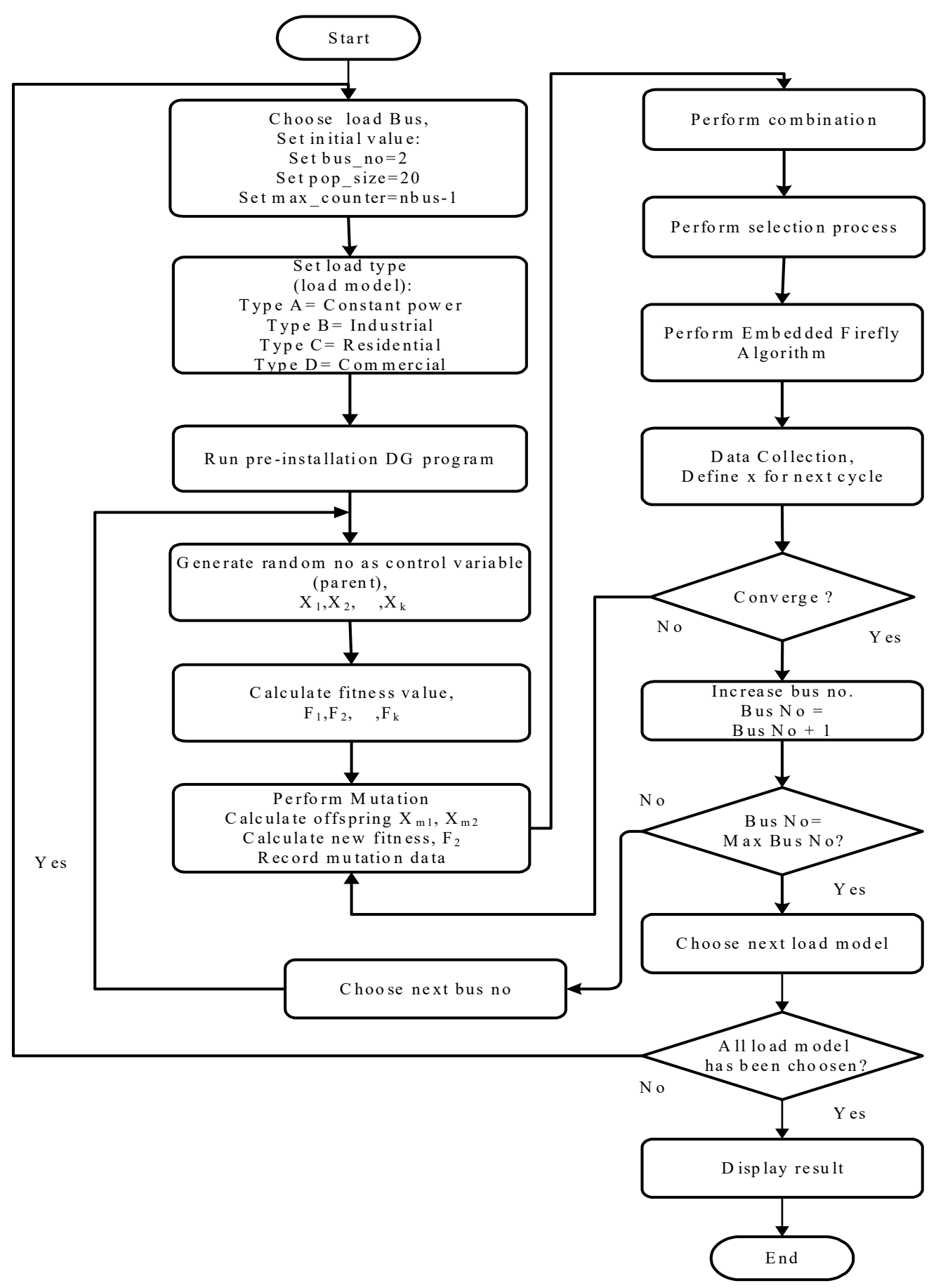

Fig. 1. Flowchart for complete Ranking Identification using the EMEFA technique of DG planning 
Further study also presented the development of the Loss Reduction Index (LRI) as shown in equation (5). This index is derived from the total losses obtained from the based case that will be compared to the total losses with the DG installation in the system. The highest percentage of LRI indicates the more loss reduction in the system. The result obtained from this index can contribute to the DG planner to allocate the suitable DG location in the system based on the percentage of LRI.

$$
\begin{gathered}
\text { Of }=\min \left(P_{\text {loss }}=\sum_{i=1}^{n} \sum_{j=1}^{n} A_{i j}\left(P_{i} P_{j}+Q_{i} Q_{j}\right)+B_{i j}\left(Q_{i} P_{j}-P_{i} Q_{j}\right)\right) \\
L R I=\frac{\left({\text { Total } \left.\operatorname{Loss}_{0}-\text { Total Loss }_{D G}\right)}_{\text {Total Loss }}\right.}{\operatorname{Lot}_{0}} \times 100 \%
\end{gathered}
$$

Where TotalLoss ${ }_{0}=$ Total loss without DG in MW and TotalLoss ${ }_{\mathrm{DG}}=$ Total Loss with DG in MW.

The load models are very much influenced by the nature of DG types [6]. Each tested scenario will consider all the 4 load models. Integration between techniques, scenarios and load model is called study cases. The general scenario depends on DG type as shown in Table 1. In this table, the lists of possible scenarios for DG installation dependent on load model is tabulated for different DG type.

Table 1. Scenarios of case study considering DG installation dependent on load model.

\begin{tabular}{|c|c|c|c|c|c|}
\hline \multirow{2}{*}{$\begin{array}{c}\text { Case } \\
\text { Study }\end{array}$} & Scenario & \multicolumn{4}{|c|}{ Load Model } \\
\hline A & Model 1 & Model 2 & Model 3 & Model 4 \\
\cline { 2 - 6 } (DG & I-1000 & 1 & 0 & 0 & 0 \\
\cline { 2 - 6 } Type & I-0100 & 0 & 1 & 0 & 0 \\
\cline { 2 - 6 } I) & I-0010 & 0 & 0 & 1 & 0 \\
\hline B & II-1000 & 1 & 0 & 0 & 1 \\
\hline (DG & II-0100 & 0 & 1 & 0 & 0 \\
\cline { 2 - 6 } Type & II-0010 & 0 & 0 & 1 & 0 \\
\cline { 2 - 6 } II) & II-0001 & 0 & 0 & 0 & 1 \\
\hline C & III-1000 & 1 & 0 & 0 & 0 \\
\cline { 2 - 6 } (DG & III-0100 & 0 & 1 & 0 & 0 \\
\cline { 2 - 6 } Type & III-0010 & 0 & 0 & 1 & 0 \\
\hline III) & III-0001 & 0 & 0 & 0 & 1 \\
\hline D & IV-1000 & 1 & 0 & 0 & 0 \\
\hline (DG & IV-0100 & 0 & 1 & 0 & 0 \\
\hline Type & IV-0010 & 0 & 0 & 1 & 0 \\
\cline { 2 - 6 } IV) & IV-0001 & 0 & 0 & 0 & 1 \\
\hline
\end{tabular}

The ranking identification technique was conducted in order to identify the suitable location for DG planning. The DG was located at all bus individually except slack bus. The simulation is identified automatically based on the optimal DG sizing for every single unit of DG at all busses individually to determine the total loss in the system. Then, the total loss will be ranked in descending order to identify the minimum total loss for each DG location. The pre-developed EMEFA technique was performed with an objective function is to minimize the total losses in the system [7]. The complete algorithm of ranking identification using the EMEFA technique for DG planning is demonstrated in Fig. 1.

\section{Results and discussion}

This section describes the results of the Ranking Identification technique in order to determine the suitability of DG planning in the distribution system. The simulation is identified automatically based on the optimal DG sizing for every single unit of DG at all busses individually to determine the total loss in the system. Then, the total loss will be ranked in ascending order to identify the minimum total loss for each DG location for the possible scenarios of case study for Ranking Identification technique considering DG installation dependent on load model. To address the effectiveness of the proposed technique for DG planning, several scenarios have been considered. The scenario will not be consistent for both test systems.

The proposed technique was performed for DG location and planning on IEEE 33-Bus Distribution System. The simulation is identified automatically based on the optimal DG sizing for every single unit of DG at all buses individually to determine the total loss in the system. In this study, the DG was tested into 32 load buses individually. Then, the results for total loss will be recorded and ranked in descending order to identify the minimum total loss for each DG location. In this analysis, the results of the DG location, DG sizing and total loss are recorded and the results are tabulated the top five locations that are chosen as the suitable location.

\section{a) DG Type 1 (Case A)}

In this scenario, the analysis was done for different DG type and load model. The DG is located as dependent on the load model using Ranking Identification technique. Table 2 indicates the results for Scenario I-1000 until I0001. For the first scenario I-1000, the DG is modelled as type I and load is modelled as constant load. The Ranking Identification technique tabulated the top five of suitable location at bus 25, 26, 27, 28 and 29 with the minimum total loss is located at bus 25 with $0.097 \mathrm{MW}$. From the table, the value for DG size is the optimized DG values. For bus 25, the optimal DG size is 2.2076 MW. The total loss is evaluated based on the objective function to minimize total loss in the system. The minimum and maximum voltage was recorded in order to show the improvement of the voltage profile with the existing of DG unit.

Comparable study was performed for scenario I0100. The result ranked the suitable location at bus 30 , $25,26,29$ and 27 based on minimum total loss as objective function. The minimum total loss is located at bus 30 with $0.0767 \mathrm{MW}$ and the optimal DG size is $1.3690 \mathrm{MW}$. For scenario I-0010, the result is ranked the location of DG at bus 30,25, 26, 27 and 29 with the minimum total loss is $0.0816 \mathrm{MW}$ at bus 30 . Lastly, the determination of DG location is located for Scenario I0001 . The result is ranked the location of DG at bus 30 , 25, 26, 27 and 29. The minimum total loss at bus 30 with the optimal DG size is $1.3440 \mathrm{MW}$ and the total loss is 0.0837 MW. 


\section{b) DG Type II (Case B)}

In this scenario, the DG is modelled as Type II, which is the DG is capable of injecting reactive power. A comparative study was performed to consider the impact on the different load model. Table 3 indicates the results for Scenario II-1000 until II-0001. For the first scenario II-1000, the DG is modelled as Type I and load is modelled as constant load. The Ranking Identification technique tabulated the suitable location at bus 30, 29, 31,28 and 32 with the minimum total loss is located at bus 30 with $0.1190 \mathrm{MW}$. From the table, the optimal DG size for bus 30 is 1.1862 MVAR.

The similar study was performed for scenario II0100 . The result ranked the suitable location at bus 30 , $29,31,32$ and 33 based on minimum total loss as objective function. The minimum total loss is located at bus 30 with $0.1185 \mathrm{MW}$ and the optimal DG size is 0.8513 MVAR. The next scenario II- 0010 also indicates the suitable location at bus $30,29,31,32$ and 33 with the minimum total loss is located at bus 30 with 0.9136 MVAR. The similar study was performed for scenario II-0001. The minimum total loss is located at bus 30 with $0.1150 \mathrm{MW}$ and the optimal DG size is 0.9328 MVAR.

\section{c) DG Type III (Case C33)}

To further investigate the effect of different DG type and load model, the DG is modelled as type III, which is the DG is capable of injecting reactive power. A similar study was performed for Scenario III-1000 until III-0001 and the results is presented in the Table 4. In scenario III-1000, the load is modelled as constant load. This Ranking Identification technique tabulated the suitable location at bus $30,29,28,27$ and 26 with the minimum total loss is located at bus 30 with $0.0537 \mathrm{MW}$ and the optimal DG size is $1.3386 \mathrm{MW}$ and $0.6780 \mathrm{MVAR}$. The total loss is evaluated based on the objective function to minimize total loss in the system. The minimum and maximum voltage was recorded in order to show the improvement of the voltage profile with the existing of DG unit.

Similar study was performed for scenario III-0100. The result ranked the suitable location at bus 30, 29, 28, 27 and 26 based on minimum total loss as objective function. The minimum total loss is located at bus 30 with $0.0537 \mathrm{MW}$ and the optimal DG size is $1.3353 \mathrm{MW}$ and 0.6764 MVAR. The next scenario I-0010 also indicates the suitable location at bus 30,29, 28, 27 and 26 with the minimum total loss is located at bus 30 with $0.0537 \mathrm{MW}$. From the simulation, the optimal DG sizing is $1.3236 \mathrm{MW}$ and $0.6704 \mathrm{MVAR}$. The similar study was performed for scenario I-0001. The minimum total loss is located at bus 30 with $0.0537 \mathrm{MW}$ and the optimal DG size is $1.3025 \mathrm{MW}$ and 0.658 MVAR.
Table 2 Result for Case A

\begin{tabular}{|c|c|c|c|c|}
\hline \multicolumn{5}{|c|}{ Scenario I-1000 } \\
\hline \multirow{2}{*}{$\begin{array}{c}\text { DG } \\
\text { Location }\end{array}$} & \multicolumn{2}{|c|}{ DG Size } & \multicolumn{2}{|c|}{ Total Loss } \\
\hline & $\mathrm{P}_{\mathrm{DG}}(\mathrm{MW})$ & $\mathrm{Q}_{\mathrm{DG}}$ (MVAR) & Ploss (MW) & Qloss (MVAR) \\
\hline 25 & 2.2076 & 0 & 0.097 & 0.0704 \\
\hline 26 & 2.0514 & 0 & 0.0977 & 0.0704 \\
\hline 27 & 1.9862 & 0 & 0.0985 & 0.0707 \\
\hline 28 & 1.6448 & 0 & 0.1001 & 0.0711 \\
\hline 29 & 1.4795 & 0 & 0.1005 & 0.0706 \\
\hline \multicolumn{5}{|c|}{ Scenario I-0100 } \\
\hline \multirow{2}{*}{$\begin{array}{c}\text { DG } \\
\text { Location }\end{array}$} & \multicolumn{2}{|c|}{ DG Size } & \multicolumn{2}{|c|}{ Total Loss } \\
\hline & $\mathrm{P}_{\mathrm{DG}}(\mathrm{MW})$ & $\mathrm{Q}_{\mathrm{DG}}(\mathrm{MVAR})$ & Ploss (MW) & Qloss (MVAR) \\
\hline 30 & 1.369 & 0 & 0.0767 & 0.0543 \\
\hline 25 & 2.1738 & 0 & 0.0933 & 0.0681 \\
\hline 26 & 2.1118 & 0 & 0.0971 & 0.0702 \\
\hline 29 & 1.473 & 0 & 0.0975 & 0.0685 \\
\hline 27 & 1.987 & 0 & 0.0979 & 0.0703 \\
\hline \multicolumn{5}{|c|}{ Scenario I-0010 } \\
\hline DG & \multicolumn{2}{|c|}{ DG Size } & \multicolumn{2}{|c|}{ Total Loss } \\
\hline Location & $\mathrm{P}_{\mathrm{DG}}(\mathrm{MW})$ & $\mathrm{Q}_{\mathrm{DG}}(\mathrm{MVAR})$ & Ploss (MW) & Qloss (MVAR) \\
\hline 30 & 1.3586 & 0 & 0.0816 & 0.0575 \\
\hline 25 & 2.1856 & 0 & 0.0943 & 0.0688 \\
\hline 26 & 2.1163 & 0 & 0.0972 & 0.0703 \\
\hline 27 & 1.9704 & 0 & 0.098 & 0.0704 \\
\hline 29 & 1.4429 & 0 & 0.0982 & 0.0689 \\
\hline \multicolumn{5}{|c|}{ Scenario I-0001 } \\
\hline DG & \multicolumn{2}{|c|}{ DG Size } & \multicolumn{2}{|c|}{ Total Loss } \\
\hline Location & $\mathrm{P}_{\mathrm{DG}}(\mathrm{MW})$ & $\mathrm{Q}_{\mathrm{DG}}(\mathrm{MVAR})$ & Ploss (MW) & Qloss (MVAR) \\
\hline 30 & 1.344 & 0 & 0.0837 & 0.0589 \\
\hline 25 & 2.1642 & 0 & 0.0946 & 0.069 \\
\hline 26 & 2.1383 & 0 & 0.0973 & 0.0704 \\
\hline 27 & 1.9722 & 0 & 0.0981 & 0.0704 \\
\hline 29 & 1.4542 & 0 & 0.0985 & 0.0692 \\
\hline
\end{tabular}

Table 3 Result for case study B33

\begin{tabular}{|c|c|c|c|c|}
\hline \multicolumn{5}{|c|}{ Scenario II-1000 } \\
\hline \multirow{2}{*}{$\begin{array}{c}\text { DG } \\
\text { Location }\end{array}$} & \multicolumn{2}{|c|}{ DG Size } & \multicolumn{2}{|c|}{ Total Loss } \\
\hline & $\mathrm{P}_{\mathrm{DG}}(\mathrm{MW})$ & $\mathrm{Q}_{\mathrm{DG}}(\mathrm{MVAR})$ & Ploss (MW) & Qloss (MVAR) \\
\hline 30 & 0 & 1.1862 & 0.119 & 0.0783 \\
\hline 29 & 0 & 1.2278 & 0.1209 & 0.0795 \\
\hline 31 & 0 & 1.028 & 0.1244 & 0.0829 \\
\hline 28 & 0 & 1.3216 & 0.1248 & 0.083 \\
\hline 32 & 0 & 0.9809 & 0.1261 & 0.0845 \\
\hline \multicolumn{5}{|c|}{ Scenario II-0100 } \\
\hline DG & \multicolumn{2}{|c|}{ DG Size } & \multicolumn{2}{|c|}{ Total Loss } \\
\hline Location & $\mathrm{P}_{\mathrm{DG}}(\mathrm{MW})$ & $\mathrm{Q}_{\mathrm{DG}}$ (MVAR) & Ploss (MW) & Qloss (MVAR) \\
\hline 30 & 0 & 0.8513 & 0.1185 & 0.0781 \\
\hline 29 & 0 & 1.1844 & 0.1206 & 0.0793 \\
\hline 31 & 0 & 0.9838 & 0.1239 & 0.0826 \\
\hline 28 & 0 & 1.2911 & 0.1247 & 0.0829 \\
\hline 32 & 0 & 0.9097 & 0.1254 & 0.084 \\
\hline \multicolumn{5}{|c|}{ Scenario II-0010 } \\
\hline DG & \multicolumn{2}{|c|}{ DG Size } & \multicolumn{2}{|c|}{ Total Loss } \\
\hline Location & $\mathrm{P}_{\mathrm{DG}}(\mathrm{MW})$ & $\mathrm{Q}_{\mathrm{DG}}$ (MVAR) & Ploss (MW) & Qloss (MVAR) \\
\hline 30 & 0 & 0.9136 & 0.1164 & 0.0767 \\
\hline 29 & 0 & 1.1991 & 0.1195 & 0.0786 \\
\hline 31 & 0 & 0.9957 & 0.1223 & 0.0815 \\
\hline 32 & 0 & 0.9419 & 0.123 & 0.0825 \\
\hline 28 & 0 & 1.3239 & 0.1243 & 0.0827 \\
\hline \multicolumn{5}{|c|}{ Scenario II-1000 } \\
\hline DG & \multicolumn{2}{|c|}{ DG Size } & \multicolumn{2}{|c|}{ Total Loss } \\
\hline Location & $\mathrm{P}_{\mathrm{DG}}(\mathrm{MW})$ & $\mathrm{Q}_{\mathrm{DG}}(\mathrm{MVAR})$ & Ploss (MW) & Qloss (MVAR) \\
\hline 30 & 0 & 0.9328 & 0.115 & 0.0758 \\
\hline 29 & 0 & 1.195 & 0.1187 & 0.0781 \\
\hline 31 & 0 & 0.9921 & 0.1211 & 0.0807 \\
\hline 32 & 0 & 0.9224 & 0.1213 & 0.0812 \\
\hline 28 & 0 & 1.3045 & 0.1239 & 0.0825 \\
\hline
\end{tabular}


Table 4 Result for case study C33

\begin{tabular}{|c|c|c|c|c|}
\hline \multicolumn{5}{|c|}{ Scenario III-1000 } \\
\hline \multirow{2}{*}{$\begin{array}{c}\text { DG } \\
\text { Location }\end{array}$} & \multicolumn{2}{|c|}{ DG Size } & \multicolumn{2}{|c|}{ Total Loss } \\
\hline & $\mathrm{P}_{\mathrm{DG}}(\mathrm{MW})$ & $\mathrm{Q}_{\mathrm{DG}}(\mathrm{MVAR})$ & Ploss (MW) & Qloss (MVAR) \\
\hline 30 & 1.3386 & 0.678 & 0.0537 & 0.0402 \\
\hline 29 & 1.4252 & 0.7219 & 0.0546 & 0.0412 \\
\hline 28 & 1.5774 & 0.799 & 0.0576 & 0.0448 \\
\hline 27 & 1.9062 & 0.9655 & 0.0604 & 0.0487 \\
\hline 26 & 2.0233 & 1.0248 & 0.0608 & 0.0492 \\
\hline \multicolumn{5}{|c|}{ Scenario III-0100 } \\
\hline DG & \multicolumn{2}{|c|}{ DG Size } & \multicolumn{2}{|c|}{ Total Loss } \\
\hline Location & $\mathrm{P}_{\mathrm{DG}}(\mathrm{MW})$ & $\mathrm{Q}_{\mathrm{DG}}(\mathrm{MVAR})$ & Ploss (MW) & Qloss (MVAR) \\
\hline 30 & 1.3353 & 0.6764 & 0.0537 & 0.0402 \\
\hline 29 & 1.4114 & 0.7149 & 0.0546 & 0.0411 \\
\hline 28 & 1.573 & 0.7967 & 0.0576 & 0.0448 \\
\hline 27 & 1.905 & 0.9649 & 0.0604 & 0.0487 \\
\hline 26 & 2.0217 & 1.024 & 0.0608 & 0.0492 \\
\hline \multicolumn{5}{|c|}{ Scenario III-0010 } \\
\hline DG & \multicolumn{2}{|c|}{ DG Size } & \multicolumn{2}{|c|}{ Total Loss } \\
\hline Location & $\mathrm{P}_{\mathrm{DG}}(\mathrm{MW})$ & $\mathrm{Q}_{\mathrm{DG}}(\mathrm{MVAR})$ & Ploss (MW) & Qloss (MVAR) \\
\hline 30 & 1.3236 & 0.6704 & 0.0537 & 0.0402 \\
\hline 29 & 1.3993 & 0.7088 & 0.05461 & 0.0411 \\
\hline 28 & 1.5652 & 0.7928 & 0.0576 & 0.0448 \\
\hline 27 & 1.8727 & 0.9486 & 0.0605 & 0.0488 \\
\hline 26 & 2.008 & 1.0171 & 0.0608 & 0.0492 \\
\hline \multicolumn{5}{|c|}{ Scenario III-0001 } \\
\hline DG & \multicolumn{2}{|c|}{ DG Size } & \multicolumn{2}{|c|}{ Total Loss } \\
\hline Location & $\mathrm{P}_{\mathrm{DG}}(\mathrm{MW})$ & $\mathrm{Q}_{\mathrm{DG}}(\mathrm{MVAR})$ & Ploss (MW) & Qloss (MVAR) \\
\hline 30 & 1.3025 & 0.6597 & 0.0537 & 0.0402 \\
\hline 29 & 1.3954 & 0.7068 & 0.0546 & 0.0411 \\
\hline 28 & 1.5654 & 0.7929 & 0.0576 & 0.0448 \\
\hline 27 & 1.8978 & 0.9613 & 0.0604 & 0.0487 \\
\hline 26 & 2.014877 & 1.0206 & 0.0608 & 0.0492 \\
\hline
\end{tabular}

\section{d) DG Type IV (Case D33)}

To compare the effect of different DG type, similar study was performed for case D33. The DG is modelled as type IV, which is the DG is capable of injecting active power while consuming the reactive power.

The results are obtained from Ranking Identification technique was tabulated in Table 5. It indicates the results for Scenario IV-1000 until IV-0001. For the first scenario I-1000, the load is modelled as constant load. The results are tabulated the suitable location at bus 30 , 29, 28, 27 and 26. The minimum total loss is located at bus 30 with $0.0537 \mathrm{MW}$. The value for DG size is $1.3405 \mathrm{MW}$ and consumes $0.679 \mathrm{MVAR}$. The results for scenario IV-0010 till IV-0001 the also indicates the top five locations at bus $30,29,31,32$ and 33 with the minimum total loss is located at bus 30 . Based on the analysis, the different load model does not affect the DG sizing and the voltage profile for the system.

Further analysis was done by determining the LRI for different scenario and the result is illustrated in Fig. 2. For Case A, the results at bus 25 indicate the highest LRI at case I-0100 with $55.26 \%$, followed with the Case I0010 at $52.37 \%$ as illustrated on the graph in Fig. 2(a). The percentage of LRI for Case I-0001 is $51.14 \%$ and the minimum LRI at Case I-1000 with $43.38 \%$. The result for DG located at bus 26, 27, 28 and 29 shows. Based on the results, the load model for industrial load gives the highest LRI followed by the residential, commercial and constant load.
Table 5 Result for case study D33

\begin{tabular}{|c|c|c|c|c|}
\hline \multicolumn{5}{|c|}{ Scenario IV-1000 } \\
\hline \multirow{2}{*}{$\begin{array}{c}\text { DG } \\
\text { Location }\end{array}$} & \multicolumn{2}{|c|}{ DG Size } & \multicolumn{2}{|c|}{ Total Loss } \\
\hline & $\mathrm{P}_{\mathrm{DG}}(\mathrm{MW})$ & $\mathrm{Q}_{\mathrm{DG}}(\mathrm{MVAR})$ & Ploss (MW) & Qloss (MVAR) \\
\hline 30 & 1.3447 & -1.9489 & 0.0538 & 0.0403 \\
\hline 29 & 1.4169 & -0.4095 & 0.0546 & 0.0412 \\
\hline 28 & 1.5772 & -2.7462 & 0.0576 & 0.0449 \\
\hline 27 & 1.9082 & -2.0788 & 0.0605 & 0.0488 \\
\hline 26 & 2.0105 & -1.4771 & 0.0609 & 0.0493 \\
\hline \multicolumn{5}{|c|}{ Scenario IV-0100 } \\
\hline \multirow{2}{*}{$\begin{array}{c}\text { DG } \\
\text { Location }\end{array}$} & \multicolumn{2}{|c|}{ DG Size } & \multicolumn{2}{|c|}{ Total Loss } \\
\hline & $\mathrm{P}_{\mathrm{DG}}(\mathrm{MW})$ & $\mathrm{Q}_{\mathrm{DG}}$ (MVAR) & Ploss (MW) & Qloss (MVAR) \\
\hline 30 & 1.3347 & -2.1756 & 0.0537 & 0.0403 \\
\hline 29 & 1.4159 & -1.3634 & 0.0546 & 0.0412 \\
\hline 28 & 1.5761 & -2.8988 & 0.0576 & 0.0449 \\
\hline 27 & 1.9156 & -2.1981 & 0.0605 & 0.0488 \\
\hline 26 & 2.0228 & -2.213 & 0.0608 & 0.0493 \\
\hline \multicolumn{5}{|c|}{ Scenario IV-0010 } \\
\hline \multirow{2}{*}{$\begin{array}{c}\text { DG } \\
\text { Location }\end{array}$} & \multicolumn{2}{|c|}{ DG Size } & \multicolumn{2}{|c|}{ Total Loss } \\
\hline & $\mathrm{P}_{\mathrm{DG}}(\mathrm{MW})$ & $\mathrm{Q}_{\mathrm{DG}}(\mathrm{MVAR})$ & Ploss (MW) & Qloss (MVAR) \\
\hline 30 & 1.3218 & -1.5812 & 0.0538 & 0.0403 \\
\hline 29 & 1.4044 & -3.8557 & 0.0546 & 0.0412 \\
\hline 28 & 1.5583 & -1.2274 & 0.0576 & 0.0449 \\
\hline 27 & 1.9096 & -0.3885 & 0.0605 & 0.0488 \\
\hline 26 & 2.0184 & -4.9472 & 0.0608 & 0.0493 \\
\hline \multicolumn{5}{|c|}{ Scenario IV-0001 } \\
\hline \multirow{2}{*}{$\begin{array}{c}\text { DG } \\
\text { Location }\end{array}$} & \multicolumn{2}{|c|}{ DG Size } & \multicolumn{2}{|c|}{ Total Loss } \\
\hline & $\mathrm{P}_{\mathrm{DG}}(\mathrm{MW})$ & $\mathrm{Q}_{\mathrm{DG}}$ (MVAR) & Ploss (MW) & Qloss (MVAR) \\
\hline 30 & 1.2998 & -2.1713 & 0.0537 & 0.0403 \\
\hline 29 & 1.3889 & -2.5971 & 0.0546 & 0.0412 \\
\hline 28 & 1.5511 & -2.5921 & 0.0576 & 0.0449 \\
\hline 27 & 1.8984 & -1.367 & 0.0605 & 0.0488 \\
\hline 26 & 2.0152 & -5.0073 & 0.0608 & 0.0493 \\
\hline
\end{tabular}

For Case B, the results at bus 30 indicate the highest LRI compared to others cases. The result shows the similar trends for each case for DG located at bus 29, 31, 32 and 28. Based on the results, the load model for industrial gives the highest LRI followed by the commercial, residential and constant load.

Similar study was performed for LRI for Case C. From the graph in Fig 2 (c), the results at bus 30 show the highest LRI at all cases with the percentage is 68.64 $\%$. This result shows different trends compared to Case A and B. In Case C, when the DG is installed as type III, it is found that the different load model does not affect the total loss. In the meantime, the result shows the LRI remains the same for all scenarios. This result shows similar trends in Case D, when the DG is installed for active and consumes reactive power. It is found that the different load model does not affect the total loss. In the meantime, the result shows the LRI remains the same for all scenarios.

\section{Conclusion}

The analysis of load model which considers the loss minimization and the voltage performance was successfully implemented and tested on IEEE 33 and IEEE 69 bus test system. The Ranking Identification technique using EMEFA is used to determine the optimal output of DG with different DG type and load models. The ranking identification technique is developed in order to determine the suitability of DG planning in the distribution system. This technique was conducted using the developed automatic algorithm for 
single DG by incorporating the EMEFA technique as optimization technique. The simulation is identified automatically based on the optimal DG sizing for every single unit of DG at all busses individually to determine the total loss in the system. Then, the total loss will be ranked in descending order to identify the minimum total loss for each DG location. The modeling of voltage dependent loads, i.e. residential, commercial and industrial loads have been presented and the results show the voltage dependent load models have a significant effect on total losses of a distribution system for different DG type consequently would affect the loss of the system.

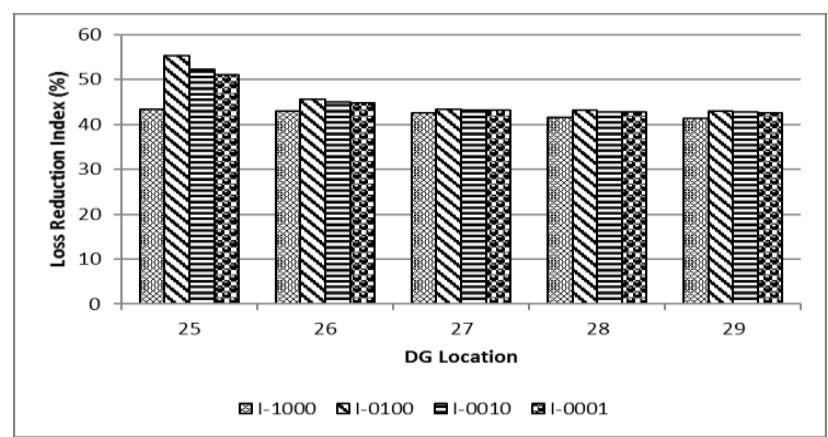

(a) DG Type 1 (Case A)

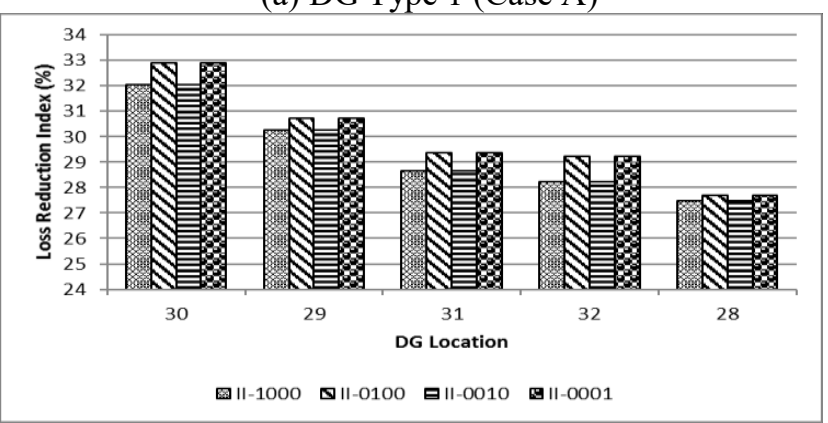

(b) DG Type II (Case B)

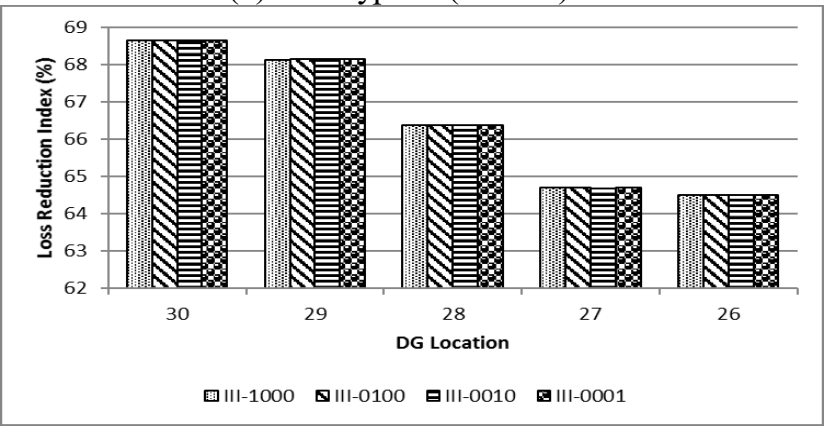

(c) DG Type III (Case C)

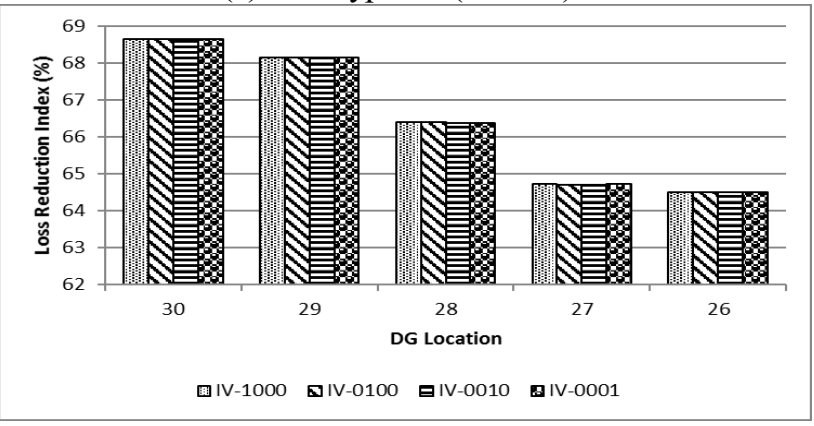

(d) DG Type IV (Case D)

Fig. 2. Comparative study on LRI for different scenario
The authors would like to acknowledge Centre of Excellence for Renewable Energy (CERE), UniMAP, School of Electrical System Engineering, UniMAP, Ministry of Higher Education Malaysia (MOHE) and Universiti Malaysia Perlis for the financial support of this research. This research is supported by MOHE under the Fundamental Research Grant Scheme with project code: (File No: FRGS/1/2016/TK04/UNIMAP/02/9).

\section{References}

1. Z. M. Yasin, T. K. A. Rahman, I. Musirin, and S. R. A. Rahim, "Optimal sizing of distributed generation by using quantum-inspired evolutionary programming," 4th Int. Power Eng. Optim. Conf., 2010.

2. S. R. A. Rahim, I. Musirin, M. H. H. Hussain, and M. M. M. Othman, "EMEFA Approach for DG Installation in Distribution System," Int. Rev. Model. Simulations, vol. 5, no. 6, pp. 2546-2553, 2012.

3. A. K. Bohre, G. Agnihotri, M. Dubey, and S. Kalambe, "Impacts of the Load Models on Optimal Planning of Distributed Generation in Distribution System," Electr. Eng. Dep. Azad Natl. Inst. Technol. (MANIT), Bhopal 462003, India, vol. 2015, pp. 110, 2015.

4. H. Nasiraghdam and S. Jadid, "Load model effect assessment on optimal distributed generation (DG) sizing and allocation using improved harmony search algorithm," Conference on Smart Electric Grids Technology (SEGT), 2013, pp. 210-218.

5. A. Zidan, R. S. Al-Abri, and E. F. El-Saadany, "Load model effect on distributed generation allocation and feeders' reconfiguration in unbalanced distribution systems," 2015 IEEE 8th GCC Conf. Exhib. GCCCE 2015, pp. 1-4, 2015.

6. A. M. El-Zonkoly, "Optimal placement of multidistributed generation units including different load models using particle swarm optimisation," IET Gener. Transm. Distrib., vol. 5, no. 7, p. 760, 2011.

7. S. R. A. Rahim, Muhammad Murthadha Othman, and I. Musirin, "Clustering Technique for DG Planning Considering Load Models," Appl. Mech. Mater., vol. 793, no. August 2016, pp. 457-461, 2015. 